\title{
Indicators of Psychiatric Disorders in Different Oncology Specialties: A Prevalence Study
}

\author{
Manuela Polidoro Lima' and Flávia L. Osório ${ }^{1,2}$ \\ ${ }^{1}$ Fundação Pio XII, Hospital de Câncer de Barretos, Rua Antenor Antonio Vilela 1331, 14780-000 Barretos, SP, Brazil \\ ${ }^{2}$ Faculdade de Medicina de Ribeirão Preto, Universidade de São Paulo, 14048-900 Ribeirão Preto, SP, Brazil \\ Correspondence should be addressed to Flávia de L. Osório; flaliosorio@ig.com.br
}

Received 21 December 2013; Revised 28 February 2014; Accepted 20 March 2014; Published 14 April 2014

Academic Editor: Richard T. Penson

Copyright (C) 2014 M. Polidoro Lima and F. L. Osório. This is an open access article distributed under the Creative Commons Attribution License, which permits unrestricted use, distribution, and reproduction in any medium, provided the original work is properly cited.

\begin{abstract}
Objective. This study evaluated the prevalence of various indicators of psychiatric disorders in Brazilian outpatients with cancer and assessed possible associations with sociodemographic indicators. Materials and Methods. A total of 1,385 patients were evaluated using the following instruments: Patient Health Questionnaire-4 (PHQ-4), Generalized Anxiety Disorder (GAD-7), Fagerström Test for Nicotine Dependence (FTND), and Fast Alcohol Screening Test (FAST). Results. The sample was composed of both genders with a slight predominance of women (55.8\%), subjects with incomplete/completed elementary school (59\%), married (67.4\%), with children (94\%), not active from a labor viewpoint (61.6\%), and following some type of religion (79.5\%). The prevalence of anxiety for the total sample varied between 21.5 and $27.4 \%$. The prevalence of depression was $21.1 \%$, tobacco abuse/dependence was $40.2 \%$, and alcohol was $20.3 \%$. Women had significantly higher levels of anxiety and depression than men. Men had higher levels of substance abuse/dependence indicators than women. Conclusion. These results are consistent with the literature, which attests to the high prevalence of psychiatric disorder indicators in cancer patients, especially compared to the general population.
\end{abstract}

\section{Introduction}

The term "cancer" refers to a set of conditions that have the growth of cells that invade tissues and organs of the human body in common [1]. The causes of cancer are varied, but psychological and behavioral factors such as chronic stress, depression, and social isolation may contribute to the initiation and progression of certain cancers $[2,3]$.

Conversely, cancer is a risk factor for the development of mental disorders. Symptoms of psychological and physical distress may emerge during cancer treatment in combination with disease systems [4-6].

Attention to the psychosocial aspects of the disease is equally important to cancer treatment [7], especially regarding psychopathologies because they significantly impact morbidity, low adherence to treatment, hospitalization duration, prognosis, quality of life, and patient survival [8-11].

The estimated prevalence of psychiatric disorders in individuals with cancer is approximately 20 to $50 \%$ [12-14], and depression exhibits the highest rates [15-18].
Psychiatric disorders and symptoms may represent an adjustment reaction to the disease condition, and these symptoms may also be associated with a general medical condition, such as delirium [19]. Clinical complications and metabolic changes, such as hypercalcemia, anemia, vitamin B12 deficiency, and electrolyte imbalance, are also risk factors for mental disorders in cancer patients, especially depression [18].

Therefore, the impact of the cancer and the associated clinical conditions may promote the development of psychiatric disorders, especially mood disorders and psychotic symptoms [20, 21].

Anxiety symptoms are commonly found in cancer patients. Pathological anxiety may be present in physical diseases, medication and drug use, alcohol withdrawal, central nervous system depressants, and the so-called anxiety disorders $[22,23]$. The prevalence of anxiety in cancer patients varies between 10 and $30 \%[24,25]$, and it is often associated with the diagnosis stage, procedure performance, and uncertainty about the future $[20,21]$. 
The abuse of psychoactive substances is directly associated with physical diseases, such as cirrhosis, cancer, and cardiovascular disease [26]. The consumption of alcohol and tobacco is a well-established and prominent etiological factor in patients with malignancy in the lungs and esophagus [27].

Various mental disorders are risk factors for the development of some cancers. Mental disorders may appear as comorbidities with the clinical condition, which may negatively impact disease diagnosis and treatment and emotional and financial costs [9-11].

However, oncology clinicians poorly identify mental disorders and their most common symptoms, despite the good responses to pharmacological and/or psychosocial interventions [28-31].

Knowledge of the prevalence of psychiatric disorders in this specific population may increase awareness and identification and mobilize resources for prevention and treatment $[6,32]$. Early screening for behavioral and/or psychological/psychiatric disorders in patients seen in health care settings positively affects health care quality and decreases suffering and institutional operational costs [33].

This study evaluated a statistically estimated sample of cancer outpatients at a hospital specializing in cancer according to the presence/absence of major mental symptoms/disorders using simple and quick screening instruments across different oncology specialties.

\section{Materials and Methods}

2.1. Subjects. The sample comprised 1,385 subjects. Statistical calculations determined that a minimum sample size of 1,155 subjects was required with an error rate of $3 \%$. The subjects were recruited from a single hospital specializing in cancer, and all subjects were receiving outpatient care (new or return cases) in different oncology specialties. The inclusion criteria were individuals of both genders over 18 years of age. The following exclusion criteria were adopted: severe cognitive impairment as qualitatively evaluated by the applicator and the absence of clinical conditions that would affect responses to the instruments.

2.2. Instruments. The following self-assessment scales were used for data collection:

(a) Patient Health Questionnaire-4 (PHQ-4) screens for depression (PHQ-4 D-brief version of PHQ-9) and anxiety (PHQ-4 A-brief version of GAD-7) indicators experienced during the prior two weeks. Pfizer (Pfizer, Inc. Copyright 2005) translated this version into Brazilian Portuguese;

(b) Generalized Anxiety Disorder (GAD-7) screens for typical indicators of anxiety disorders experienced during the prior two weeks. This instrument includes the two items from PHQ-4 A and more five items that enable screening of Generalized Anxiety Disorder. Pfizer (Pfizer, Inc. Copyright 2005) translated this version into Brazilian Portuguese; (c) Fast Alcohol Screening Test (FAST) evaluates risky, harmful use and alcohol dependence syndrome. This version was translated and validated for Brazilian Portuguese [34];

(d) Fagerström Test for Nicotine Dependence (FTND) measures the degree of physical dependence on nicotine. This version was translated and validated into Brazilian Portuguese [35].

(e) Sociodemographic and Clinical Questionnaire assesses information about sociodemographic data (gender, schooling, civil status, professional situation, and religion) and treatments in mental health.

2.3. Data Collection and Analysis. The subjects were selected randomly in reference to the scheduling system of the hospital according to the medical consultation dates. Subjects completed the questionnaires individually, and the evaluator remained available for assistance.

The data were coded according to the ethical (Local Ethics Committee-Process no. 537/2011) and technical recommendations and entered into a database for analysis. The statistical package for social sciences (SPSS) version 19 was used. Descriptive (e.g., mean, standard deviation, and percentage) and parametric statistics (e.g., Student's $t$-test, chi-square, and Pearson correlation test) were used for data analysis. A significance level of $P<0.05$ was adopted.

\section{Results}

The sample included adult individuals (mean $=50.3$; $\mathrm{DP}=13.9$ ) of both genders with a slight predominance of women $(55.8 \%)$. The sample included subjects with incomplete/completed elementary school (59\%), married or in a stable relationship (67.4\%), with children $(86.7 \%)$, and not active from a labor viewpoint (61.3\%). A total of $79.5 \%$ of the sample followed some type of religion, most often Catholicism (68\%). Approximately $80 \%$ of the sample had no previous psychiatric/psychological history or psychiatric antecedents.

The prevalence of different indicators of psychiatric disorders in the total sample and according to different oncology specialties is shown in Table 1.

Anxiety's symptoms rates between $21.4 \%$ and $27.3 \%$ were observed for the total group, and Gynecology, Mastology, and Thorax specialties were prominent (Table 1). The prevalence of depression indicators was $18.5 \%$ for the total group, and Gynecology, Orthopedics, and Thorax exhibited the highest rates.

The alcohol and tobacco abuse rates were $17.2 \%$ and $16.6 \%$, respectively. The percentage prevalence of these abuse rates was higher in the Upper Digestive, Thorax, Head and Neck, and Urology specialties, reaching levels in excess of $30 \%$.

Prevalence indicators for different sociodemographic characteristics of the sample are shown in Tables 2 and 3.

Women had higher anxiety indicators prevalence rates than men, and unmarried subjects exhibited higher anxiety rates than married subjects. This difference according to 
TABLE 1: Prevalence of different indicators of psychiatric disorders evaluated using screening instruments.

\begin{tabular}{|c|c|c|c|c|c|c|c|c|c|c|}
\hline \multirow{2}{*}{ Specialty $($ total $N)$} & \multicolumn{2}{|c|}{ PHQ-4 A } & \multicolumn{2}{|c|}{ PHQ-4 D } & \multicolumn{2}{|c|}{ GAD-7 } & \multicolumn{2}{|c|}{ FAST } & \multicolumn{2}{|c|}{ FTND } \\
\hline & $N$ & $\%$ & $N$ & $\%$ & $N$ & $\%$ & $N$ & $\%$ & $N$ & $\%$ \\
\hline Head and neck (160) & 31 & 19.4 & 24 & 15.0 & 22 & 13.8 & 31 & 19.4 & 34 & 21.4 \\
\hline Upper Digestive (140) & 30 & 21.4 & 25 & 18.0 & 26 & 18.7 & 43 & 30.7 & 29 & 20.7 \\
\hline Lower Digestive (120) & 31 & 25.8 & 23 & 19.2 & 22 & 18.3 & 24 & 20.0 & 21 & 17.5 \\
\hline Gynecology (146) & 63 & 43.2 & 44 & 30.3 & 47 & 32.6 & 17 & 11.6 & 20 & 13.8 \\
\hline Mastology (262) & 95 & 36.4 & 56 & 21.3 & 79 & 30.3 & 22 & 8.4 & 19 & 7.3 \\
\hline Melanoma (60) & 05 & 8.3 & 05 & 8.3 & 06 & 10.0 & 11 & 18.3 & 09 & 15.3 \\
\hline Neurosurgery (62) & 10 & 16.1 & 09 & 14.5 & 04 & 6.5 & 05 & 8.1 & 10 & 16.4 \\
\hline Skin (95) & 16 & 16.8 & 12 & 12.6 & 11 & 11.7 & 12 & 12.6 & 17 & 17.9 \\
\hline Thorax/Lung (76) & 30 & 39.5 & 17 & 22.4 & 20 & 26.3 & 18 & 23.7 & 19 & 25.0 \\
\hline Urology (236) & 63 & 26.8 & 35 & 14.8 & 54 & 23.0 & 52 & 22.0 & 48 & 20.3 \\
\hline Orthopedics (28) & 05 & 17.9 & 07 & 25.0 & 06 & 21.4 & 03 & 10.7 & 04 & 14.3 \\
\hline Total (1385) & 379 & 27.36 & 257 & 18.55 & 297 & 21.44 & 238 & 17.18 & 230 & 16.60 \\
\hline
\end{tabular}

N: frequency, \%: percentage, PHQ-4 A: Patient Health Questionnaire-4 A, PHQ-4 D: Patient Health Questionnaire-4 D, GAD-7: Generalized Anxiety Disorder, FAST: Fast Alcohol Screening Test, and FTND: Fagerström Test for Nicotine Dependence.

marital status was observed using the PHQ-4 A instrument, but it was not confirmed using the GAD-7 instrument.

Higher rates of symptoms of depression were associated with females, unmarried, and widowed subjects and subjects who were professionally inactive.

The rates of substance abuse (alcohol and tobacco) were more significant in men, married, and divorced individuals, subjects with less education, subjects who were not professionally active, and subjects who did not follow any religion (Table 3).

The comorbidity rate in the total sample and among different oncology specialties is also noteworthy: $27.1 \%$ of the sample exhibited at least one comorbidity, with a prevalence of cooccurrence of anxiety and depression of $11.8 \%$, and $6.6 \%$ of the sample had more than two comorbidities.

A total of $43.4 \%$ of patients in the Thorax/Lung specialty, $33.5 \%$ of the Upper Digestive specialty, and $29.8 \%$ of the Urology specialty exhibited indicators of more than one mental disorder.

\section{Discussion}

Cancer and psychiatric symptoms/disorders are strongly associated, and the present study evaluated this association in cancer outpatients undergoing treatment. Screening instruments evaluated symptoms of depression, anxiety, and substance abuse/chemical dependence.

The data showed depression indicators prevalence of $18.5 \%$, which is greater than a previous Brazilian epidemiological study of $9.4 \%$ [31] but similar to a meta-analysis that reported a $16.3 \%$ depression rate in cancer patients at clinics and cancer hospitals [36]. These data corroborate previous reports of the prevalence of depression in this clinical group.

The prevalence of anxiety indicators varied between $21.4 \%$ and $27.3 \%$, which are similar to primary care users (27.9\%) as determined using observer-assessment interviews
[37]. These data reinforce the important association between physical disease and anxiety, regardless of treatment context.

Moreover, the rate of anxiety indicators in this study is high compared to a previous study that diagnosed $7.6 \%$ of cancer patients with an anxiety disorder using a diagnostic interview [38]. However, the choice of instrument may explain this difference, and the present study used screening instruments that measure anxiety symptoms rather than specific disorders.

The prevalence rate of alcohol abuse/dependence for the total sample was $20.3 \%$. This level is higher than patients admitted to general medical specialties (9.8\%) and hospitalized cancer patients (15.5\%), who were all evaluated using a screening instrument [39].

The tobacco abuse rate for the total sample was $40.2 \%$, which was similar to the prevalence of $44 \%$ in patients admitted to gastroenterology and pulmonology wards using screening scales and diagnostic interviews [40]. However, this rate is higher than the Brazilian population (24.1\%) [37]. These findings suggest tobacco use as a possible risk factor, especially for oncological diseases of the respiratory system.

The Gynecology, Mastology, and Thorax specialties showed the highest rates of depression and anxiety indicators. One possible explanation for this finding is the exclusive presence of women in the first two specialties. Other evaluation studies of cancer patients reported that women subjects admitted to general hospitals or the general population exhibit high rates of depression and anxiety symptoms [31, 41-45]. It is possible too that, in Thorax specialty, the poorer prognosis can favor these rates [46].

One study evaluated 987 patients with lung cancer and found depressive symptoms in most subjects [47]. Another study evaluated patients with lung cancer using a selfadministered Hospital Anxiety and Depression Scale (HADS) and found that $37 \%$ had depression symptoms [48]. One possible explanation for this result is suggested by two other studies that showed an increased likelihood of depressive 
TABLE 2: Anxiety and depression indicators according to sociodemographic characteristics of the sample $(N=1385)$.

\begin{tabular}{|c|c|c|c|c|c|c|c|c|c|c|c|c|c|c|c|}
\hline \multirow{3}{*}{ Sociodemographic variables } & \multicolumn{5}{|c|}{ GAD-7 } & \multicolumn{5}{|c|}{ PHQ-4 D } & \multicolumn{5}{|c|}{ PHQ-4 A } \\
\hline & \multicolumn{2}{|c|}{ No } & \multicolumn{2}{|c|}{ Yes } & \multirow{2}{*}{ Stat. } & \multicolumn{2}{|c|}{ No } & \multicolumn{2}{|c|}{ Yes } & \multirow{2}{*}{ Stat. } & \multicolumn{2}{|c|}{ No } & \multicolumn{2}{|c|}{ Yes } & \multirow{2}{*}{ Stat. } \\
\hline & $N$ & $\%$ & $N$ & $\%$ & & $N$ & $\%$ & $N$ & $\%$ & & $N$ & $\%$ & $N$ & $\%$ & \\
\hline \multicolumn{16}{|l|}{ Gender } \\
\hline Male & 528 & 48.8 & 82 & 27.6 & $\chi^{2}=42.40$ & 545 & 48.4 & 66 & 25.7 & $\chi^{2}=43.8$ & 506 & 50.4 & 105 & 27.7 & $\chi^{2}=57.4$ \\
\hline Female & 554 & 51.2 & 215 & 72.4 & $\mathrm{P}<0.001$ & 581 & 51.6 & 191 & 74.3 & $\mathrm{P}<0.001$ & 498 & 49.6 & 27 & 72.3 & $\mathrm{P}<0.001$ \\
\hline Did not respond & & & 06 & & & & & 02 & & & & & 02 & & \\
\hline \multicolumn{16}{|l|}{ Schooling (years) } \\
\hline$\leq 09$ years & 632 & 58.4 & 183 & 61.6 & & 668 & 59.3 & 150 & 58.4 & & 598 & 59.6 & 220 & 58.0 & \\
\hline 10 to 12 years & 280 & 25.9 & 73 & 24.6 & $\chi^{2}=1.11$ & 279 & 24.8 & 74 & 28.8 & $\chi^{2}=2.63$ & 254 & 25.3 & 101 & 26.7 & $\chi^{2}=0.30$ \\
\hline$>12$ years & 170 & 15.7 & 41 & 13.8 & $P=0.57$ & 179 & 15.9 & 33 & 12.8 & $P=0.26$ & 152 & 15.1 & 58 & 15.3 & $P=0.85$ \\
\hline Did not respond & & & 06 & & & & & 02 & & & & & 02 & & \\
\hline \multicolumn{16}{|l|}{ Civil status } \\
\hline Single & 173 & 16.0 & 51 & 17.2 & & 171 & 15.2 & 53 & 20.6 & & 145 & 14.5 & 79 & 20.9 & \\
\hline Married/stable relationship & 745 & 68.9 & 184 & 62.0 & $\chi^{2}=7.46$ & 787 & 70.0 & 145 & 56.4 & $\chi^{2}=18.2$ & 708 & 70.6 & 223 & 58.8 & $\chi^{2}=18.3$ \\
\hline Divorced/separated & 90 & 8.3 & 38 & 12.8 & $P=0.58$ & 93 & 8.2 & 35 & 13.6 & $\mathrm{P}<0.001$ & 82 & 8.2 & 47 & 12.4 & $\mathrm{P}<0.001$ \\
\hline Widow/widower & 73 & 6.8 & 24 & 8.0 & & 74 & 6.6 & 24 & 9.4 & & 68 & 6.8 & 30 & 7.9 & \\
\hline Did not respond & & & 07 & & & & & 03 & & & & & 03 & & \\
\hline \multicolumn{16}{|l|}{ Professional situation } \\
\hline Active & 428 & 39.7 & 97 & 33.1 & $\chi^{2}=4.28$ & 447 & 39.9 & 79 & 31.1 & $\chi^{2}=6.79$ & 382 & 38.3 & 144 & 38.2 & $\chi^{2}=0.002$ \\
\hline Inactive & 649 & 60.3 & 196 & 66.9 & $P=0.38$ & 673 & 60.1 & 175 & 68.9 & $P=0.009$ & 615 & 61.7 & 233 & 61.8 & $P=0.96$ \\
\hline Did not respond & & & 15 & & & & & 11 & & & & & 11 & & \\
\hline \multicolumn{16}{|l|}{ Religion } \\
\hline Follows & 862 & 79.7 & 231 & 78.3 & $\chi^{2}=0.23$ & 907 & 80.6 & 191 & 74.9 & $\chi^{2}=4.07$ & 808 & 80.5 & 291 & 77.2 & $\chi^{2}=1.82$ \\
\hline Does not follow & 220 & 20.3 & 64 & 21.7 & $P=0.60$ & 219 & 19.4 & 64 & 25.1 & $P=0.44$ & 196 & 19.5 & 86 & 22.8 & $P=0.17$ \\
\hline Did not respond & & & 08 & & & & & 04 & & & & & 04 & & \\
\hline
\end{tabular}

$N$ : frequency, \%: percentage, $P$ : significance level, $\chi^{2}$ : chi-square, PHQ-4 A: Patient Health Questionnaire-4 A, PHQ-4 D: Patient Health Questionnaire-4 D, GAD-7: Generalized Anxiety Disorder, and Stat.: statistic.

episodes in subjects during nicotine withdrawal, and an even greater likelihood for patients with a history of previous depressive episodes $[49,50]$. Therefore, patients with lung cancer may begin a process of reduction or remission of their smoking habit and develop withdrawal symptoms, which promotes the onset of depression and anxiety symptoms.

Men predominated among patients abusing alcohol and tobacco, which has also been demonstrated in previous evaluations in the general population in different countries [39, 51-53]. Therefore, these high rates and the behaviors associated with the male gender, who care less about health and engage in more risky behavior [54-58], support the use of these substances as a risk factor for disease development [27, 59-63]. The higher prevalence rates of alcohol and tobacco abuse in Thorax/Lung and Upper Digestive specialty patients and patients with tumors in the head and neck confirm this hypothesis.

\section{Conclusions}

The data presented are consistent with the previous literature and attest to the high prevalence of indicators of psychiatric disorders in cancer patients, especially compared to the prevalence in the general population. These results support the conclusion that individuals with cancer are more vulnerable to the onset and development of psychiatric disorders.

Conversely, the association between substance abuse and certain cancers indicates that substance abuse can be also a risk factor for disease development.

This study was conducted using a large and statistically estimated sample, but the psychiatric indicators were evaluated using screening instruments. These instruments were validated previously and show adequate sensitivity and specificity, but they only provide the prevalence of indicators but do not indicate disorders per se. The subjects' selfperception also influences these instruments, which may be overestimated or underestimated, and this fact should be considered in data interpretation as well as the fact that all the patients come from a single treatment center.

The high rates indicate the need to screen for psychiatric disorders in cancer patients, especially because of the damaging effects that psychiatric symptoms may exert on patient treatment. Active monitoring and early detection of symptoms may facilitate treatment adherence, decrease the duration of hospital stay, and assist in disease coping.

The study also highlights the need for greater investment in prevention campaigns that discourage the use of legal substances, such as alcohol and nicotine, because these substances are risk factors in cancer development. 
TABLE 3: Substance abuse indicators according to sociodemographic characteristics of the sample $(N=1385)$.

\begin{tabular}{|c|c|c|c|c|c|c|c|c|c|c|}
\hline \multirow{3}{*}{ Sociodemographic variables } & \multicolumn{5}{|c|}{ FTND } & \multicolumn{5}{|c|}{ FAST } \\
\hline & \multicolumn{2}{|c|}{ No } & \multicolumn{2}{|c|}{ Yes } & \multirow{2}{*}{ Stat. } & \multicolumn{2}{|c|}{ No } & \multicolumn{2}{|c|}{ Yes } & \multirow{2}{*}{ Stat. } \\
\hline & $N$ & $\%$ & $N$ & $\%$ & & $N$ & $\%$ & $N$ & $\%$ & \\
\hline \multicolumn{11}{|l|}{ Gender } \\
\hline Male & 268 & 32.4 & 342 & 61.6 & $\chi^{2}=114$ & 438 & 38.2 & 174 & 73.1 & $\chi^{2}=97.47$ \\
\hline Female & 558 & 67.6 & 213 & 38.4 & $\mathrm{P}<0.001$ & 709 & 61.8 & 64 & 26.9 & $\mathrm{P}<0.001$ \\
\hline Did not respond & & & 04 & & & & & 0 & & \\
\hline \multicolumn{11}{|l|}{ Schooling (years) } \\
\hline$\leq 09$ years & 391 & 47.3 & 423 & 76.2 & & 657 & 57.3 & 161 & 67.6 & \\
\hline 10 to 12 years & 265 & 32.1 & 90 & 16.2 & $\chi^{2}=116$ & 302 & 26.3 & 53 & 22.2 & $\chi^{2}=9.97$ \\
\hline$>12$ years & 170 & 20.6 & 42 & 7.6 & $\mathrm{P}<0.001$ & 188 & 16.4 & 24 & 10.1 & $\mathbf{P}=\mathbf{0 . 0 0 7}$ \\
\hline Did not respond & & & 04 & & & & & 0 & & \\
\hline \multicolumn{11}{|l|}{ Civil status } \\
\hline Single & 138 & 16.7 & 84 & 15.2 & & 184 & 16.0 & 40 & 16.7 & \\
\hline Married/stable relationship & 554 & 67.2 & 378 & 68.1 & $\chi^{2}=3.27$ & 768 & 67.0 & 165 & 69.3 & $\chi^{2}=7.97$ \\
\hline Divorced/separated & 70 & 8.5 & 59 & 10.6 & $P=0.35$ & 103 & 9.0 & 26 & 11.0 & $\mathbf{P}=\mathbf{0 . 0 4 7}$ \\
\hline Widow/widower & 63 & 7.6 & 34 & 6.1 & & 91 & 8.0 & 07 & 3.0 & \\
\hline Did not respond & & & 05 & & & & & 0 & & \\
\hline \multicolumn{11}{|l|}{ Professional situation } \\
\hline Active & 363 & 44.3 & 164 & 29.7 & $\chi^{2}=29.5$ & 447 & 39.2 & 81 & 34.2 & $\chi^{2}=2.13$ \\
\hline Inactive & 457 & 55.7 & 388 & 70.3 & $\mathrm{P}<0.001$ & 692 & 60.8 & 156 & 65.8 & $P=0.14$ \\
\hline Did not respond & & & 13 & & & & & & & \\
\hline \multicolumn{11}{|l|}{ Religion } \\
\hline Follows & 692 & 84.0 & 405 & 73.0 & $\chi^{2}=24.7$ & 952 & 83.0 & 147 & 62.3 & $\chi^{2}=51.45$ \\
\hline Does not follow & 132 & 16.0 & 150 & 27.0 & $\mathrm{P}<0.001$ & 195 & 17.0 & 89 & 37.7 & $\mathrm{P}<0.001$ \\
\hline Did not respond & & & 06 & & & & & 0 & & \\
\hline
\end{tabular}

\section{Conflict of Interests}

The authors declare that there is no conflict of interests regarding the publication of this paper.

\section{Acknowledgment}

The authors would like to thank Núcleo de Apoio ao Pesquisador, Hospital de Câncer de Barretos Cleyton Zanardi, for helping them in the statistical analysis.

\section{References}

[1] Instituto Nacional do Câncer, Ministério da Saúde, Talking about Cancer and Its Risk Factors, Ministério da Saúde, Rio de Janeiro, Brazil, 2nd edition, 1998.

[2] E. M. V. Reiche, S. O. V. Nunes, and H. K. Morimoto, "Stress, depression, the immune system, and cancer," The Lancet Oncology, vol. 5, no. 10, pp. 617-625, 2004.

[3] J. B. Williams, D. Pang, B. Delgado et al., "A model of geneenvironment interaction reveals altered mammary gland gene expression and increased tumor growth following social isolation," Cancer Prevention Research, vol. 2, no. 10, pp. 850-861, 2009.

[4] V. A. Citero, Description and evaluation of the implementation of a psychiatric consultation-liaison service in the Research and
Treatment Centre, A.C. Camargo Cancer Hospital [M.S. thesis], Federal University of São Paulo, São Paulo, Brazil, 1999.

[5] S. B. Fleishman, "Treatment of symptom clusters: pain, depression, and fatigue," Journal of the National Cancer Institute. Monographs, no. 32, pp. 119-123, 2004.

[6] P. G. Clark, E. Rochon, D. Brethwaite, and K. K. Edmiston, "Screening for psychological and physical distress in a cancer inpatient treatment setting: a pilot study," Psycho-Oncology, vol. 20, no. 6, pp. 664-668, 2011.

[7] A. I. J. Souza and A. L. A. Erdmann, "Children diagnosed with cancer: revisiting the approach to care policies," Revista Gaúcha de Enfermagem, vol. 24, pp. 23-33, 2003.

[8] S. O. Dalton, T. M. Laursen, L. Ross, P. B. Mortensen, and C. Johansen, "Risk for hospitalization with depression after a cancer diagnosis: a nationwide, population-based study of cancer patients in Denmark from 1973 to 2003," Journal of Clinical Oncology, vol. 27, no. 9, pp. 1440-1445, 2009.

[9] J. R. Satin, W. Linden, and M. J. Phillips, "Depression as a predictor of disease progression and mortality in cancer patients: a meta-analysis," Cancer, vol. 115, no. 22, pp. 5349-5361, 2009.

[10] M. Pinquart and P. R. Duberstein, "Depression and cancer mortality: a meta-analysis," Psychological Medicine, vol. 40, no. 11, pp. 1797-1810, 2010.

[11] B. D. Bultz and C. Johansen, "Screening for distress, the 6th vital sign: where are we, and where are we going?" Psycho-Oncology, vol. 20 , no. 6 , pp. 569-571, 2011. 
[12] G. T. Deimling, B. Kahana, K. F. Bowman, and M. L. Schaeffer, "Cancer survivorship and psychological distress in later life," Psycho-Oncology, vol. 11, no. 6, pp. 479-494, 2002.

[13] L. Grassi, S. Sabato, E. Rossi, B. Biancosino, and L. Marmai, "Use of the diagnostic criteria for psychosomatic research in oncology," Psychotherapy and Psychosomatics, vol. 74, no. 2, pp. 100-107, 2005.

[14] A. Mehnert and U. Koch, "Prevalence of acute and posttraumatic stress disorder amd comorbid mental disorders in breast cancer patients during primary cancer care: a prospective study," Psycho-Oncology, vol. 16, no. 3, pp. 181-188, 2007.

[15] L. Grassi, M. Indelli, M. Marzola et al., "Depressive symptoms and quality of life in home-care-assisted cancer patients," Journal of Pain and Symptom Management, vol. 12, no. 5, pp. 300-307, 1996.

[16] W. F. Pirl, "Evidence report on the occurrence, assessment, and treatment of depression in cancer patients," Journal of the National Cancer Institute. Monographs, no. 32, pp. 32-39, 2004.

[17] J. C. Coyne, M. Stefanek, and S. C. Palmer, "Psychotherapy and survival in cancer: the conflict between hope and evidence," Psychological Bulletin, vol. 133, no. 3, pp. 367-394, 2007.

[18] S. M. B. Bottino, R. Fráguas, and W. F. Gattaz, "Depression and cancer," Revista de Psiquiatria Clinica, vol. 36, no. 3, pp. 109-115, 2009.

[19] J. Archer, I. Hutchison, and A. Korszun, "Mood and malignancy: head and neck cancer and depression," Journal of Oral Pathology and Medicine, vol. 37, no. 5, pp. 255-270, 2008.

[20] M. Pandey, G. P. Sarita, N. Devi, B. C. Thomas, B. M. Hussain, and R. Krishnan, "Distress, anxiety, and depression in cancer patients undergoing chemotherapy," World Journal of Surgical Oncology, vol. 4, article 68, 2006.

[21] P. B. Jacobsen and H. S. Jim, "Psychosocial interventions for anxiety and depression in adult cancer patients: achievements and challenges," CA. Cancer Journal for Clinicians, vol. 58, no. 4, pp. 214-230, 2008.

[22] A. House and D. Stark, "ABC of psychological medicine: anxiety in medical patients," British Medical Journal, vol. 325, no. 7357, pp. 207-209, 2002.

[23] H. S. Akiskal, "Mood disorders: clinical features," in Kaplan \& Sadock's Comprehensive Textbook of Psychiatry, B.J. Sadock and V. A. Sadock, Eds., pp. 1611-1652, Lippincott Williams \& Wilkins, Philadelphia, Pa, USA, 2005.

[24] D. W. Kissane, B. Grabsch, A. Love, D. M. Clarke, S. Blosch, and G. C. Smith, "Psychiatric disorder in women with early stage and advanced breast cancer: a comparative analysis," Australian and New Zealand Journal of Psychiatry, vol. 38, no. 5, pp. 320326, 2004.

[25] P. P. Roy-Byrne, K. W. Davidson, R. C. Kessler et al., "Anxiety disorders and comorbid medical illness," General Hospital Psychiatry, vol. 30, no. 3, pp. 208-225, 2008.

[26] G. Berrios and R. Porter, Eds., A History of Clinical Psychiatry. The Origin and History of Mental Disorders, The Athlone Press, London, UK, 1995.

[27] J. L. Kanda, "Epidemiology, diagnosis, pathology and staging of primary multiple head and neck tumors," in Treaty of Head and Neck Surgery and Otorhinolaryngology, M. B. Carvalho, Ed., pp. 277-283, Atheneu, São Paulo, Brazil, 2001.

[28] M. Lloyd-Williams, "Depression in advanced cancer-a hidden symptom," Clinical Medicine, vol. 1, no. 3, pp. 175-176, 2001.

[29] M. P. A. Fleck, B. Lafer, E. B. Sougey, J. A. del Porto, M. A. Brasil, and M. F. Juruena, "Brazilian Medical Association guidelines for the treatment of depression (full version)," Revista Brasileira de Psiquiatria, vol. 25, no. 2, pp. 114-122, 2003.

[30] D. B. Greenberg, "Barriers to the treatment of depression in cancer patients," Journal of the National Cancer Institute. Monographs, no. 32, pp. 127-135, 2004.

[31] L. H. Andrade, Y. Wang, S. Andreoni et al., "Mental disorders in megacities: findings from the São Paulo megacity mental health survey, Brazil," PLoS ONE, vol. 7, no. 2, Article ID e31879, 2012.

[32] R. D. Jones, "Depression and anxiety in oncology: the oncologist's perspective," Journal of Clinical Psychiatry, vol. 62, supplement 8, pp. 52-55, 2001.

[33] C. E. Stout and L. P. Cook, "New areas for psychological assessment in general health care settings: what to do today to prepare for tomorrow," Journal of Clinical Psychiatry, vol. 55, no. 7, pp. 797-812, 1999.

[34] C. Menezes-Gaya, A. W. Zuardi, S. R. Loureiro, and J. A. S. Crippa, "Is the Fagerström test for nicotine dependence a good instrument to assess tobacco use in patients with schizophrenia?” Revista Brasileira de Psiquiatria, vol. 31, no. 3, pp. 289-290, 2009.

[35] J. T. do Carmo and A. A. Pueyo, "Adaptation into portuguese for the Fagerström test for nicotine dependence (FTND) to evaluate the dependence and tolerance for nicotine in brazilian smokers," Revista Brasileira de Medicina, vol. 59, no. 1-2, pp. 7380, 2002.

[36] A. J. Mitchell, M. Chan, H. Bhatti et al., "Prevalence of depression, anxiety, and adjustment disorder in oncological, haematological, and palliative-care settings: a meta-analysis of 94 interview-based studies," The Lancet Oncology, vol. 12, no. 2, pp. 160-174, 2011.

[37] M. R. A. L. Molina, C. D. Wiener, J. C. Branco et al., "Prevalence of depression in users of primary care settings," Revista de Psiquiatria Clínica, vol. 39, no. 6, pp. 194-197, 2012.

[38] R. Spencer, M. Nilsson, A. Wright, W. Pirl, and H. Prigerson, "Anxiety disorders in advanced cancer patients: correlates and predictors of end-of-life outcomes," Cancer, vol. 116, no. 7, pp. 1810-1819, 2010.

[39] N. J. Botega, G. N. Mitsuushi, R. C. S. de Azevedo et al., "Depression, alcohol use disorders and nicotine dependence among patients at a general hospital," Revista Brasileira de Psiquiatria, vol. 32, no. 3, pp. 250-256, 2010.

[40] F. L. Osório, A. C. F. Carvalho, and J. A. S. Crippa, "Screening for smoking in a general hospital: scale validation, indicators of prevalence, and comorbidity," Perspectives in Psychiatric Care, vol. 49, no. 1, pp. 5-12, 2013.

[41] M. Härter, K. Reuter, A. Aschenbrenner et al., "Psychiatric disorders and associated factors in cancer: results of an interview study with patients in inpatient, rehabilitation and outpatient treatment," European Journal of Cancer, vol. 37, no. 11, pp. 13851393, 2001.

[42] N. Akhtar-Danesh and J. Landeen, "Relation between depression and sociodemographic factors," International Journal of Mental Health Systems, vol. 1, article 4, 2007.

[43] K. M. Brintzenhofe-Szoc, T. T. Levin, Y. Li, D. W. Kissane, and J. R. Zabora, "Mixed anxiety/depression symptoms in a large cancer cohort: prevalence by cancer type," Psychosomatics, vol. 50, no. 4, pp. 383-391, 2009.

[44] P. C. Fanger, R. C. S. Azevedo, M. L. F. Mauro et al., "Depression and suicidal behavior of cancer inpatients: prevalence and associated factors," Revista da Associação Médica Brasileira, vol. 56, no. 2, pp. 173-178, 2010. 
[45] J. S. Comer, C. Blanco, D. S. Hasin et al., "Health-related quality of life across the anxiety disorders: results from the National Epidemiologic Survey on Alcohol and Related Conditions (NESARC)," Journal of Clinical Psychiatry, vol. 72, no. 1, pp. 4350, 2011.

[46] L. G. Collins, C. Haines, R. Perkel, and R. E. Enck, "Lung cancer: diagnosis and management," American Family Physician, vol. 75, no. 1, pp. 56-63, 2007.

[47] P. Hopwood and R. J. Stephens, "Depression in patients with lung cancer: prevalence and risk factors derived from qualityof-life data," Journal of Clinical Oncology, vol. 18, no. 4, pp. 893903, 2000.

[48] J. A. Kramer, "Use of the hospital Anxiety and Depression Scale (HADS) in the assessment of depression in patients with inoperable lung cancer," Palliative Medicine, vol. 13, no. 4, pp. 353-354, 1999.

[49] B. C. Bock, M. G. Goldstein, and B. H. Marcus, "Depression following smoking cessation in women," Journal of Substance Abuse, vol. 8, no. 1, pp. 137-144, 1996.

[50] L. S. Covey, A. H. Classman, and F. Stetner, "Major depression following smoking cessation," American Journal of Psychiatry, vol. 154, no. 2, pp. 263-265, 1997.

[51] D. M. Burns, "Epidemiology of smoking-induced cardiovascular disease," Progress in Cardiovascular Diseases, vol. 46, no. 1, pp. 11-29, 2003.

[52] R. C. Kessler, T. C. Wai, O. Demler, and E. E. Walters, "Prevalence, severity, and comorbidity of 12-month DSM-IV disorders in the National Comorbidity Survey Replication," Archives of General Psychiatry, vol. 62, no. 6, pp. 617-627, 2005.

[53] J. R. González-López, M. A. Rodríguez-Gázquez, and M. M. Lomas-Campos, "Prevalence of alcohol, tobacco and street drug consumption in adult Latin American immigrants," Revista Latino-Americana de Enfermagem, vol. 20, no. 3, pp. 528-535, 2012.

[54] M. V. de Barros and V. N. de Arkus, "Health risk behaviors, health status self-assessment and stress perception among industrial workers," Revista de Saúde Pública, vol. 35, no. 6, pp. 554-564, 2001

[55] L. Marín-León and M. M. Vizzotto, "Driving-related behavior: an epidemiologic study of undergraduate students," Cadernos de Saúde Pública, vol. 19, no. 2, pp. 515-523, 2003.

[56] S. M. Barreto and R. C. D. Figueiredo, "Chronic diseases, self-perceived health status and health risk behaviors: gender differences," Revista de Saúde Pública, vol. 43, supplement 2, pp. 38-47, 2009.

[57] S. C. Pillon, B. O’Brien, and K. A. P. Chavez, "The relationship between drugs use and risk behaviors in Brazilian university students," Revista Latino-Americana de Enfermagem, vol. 13, no. 2, pp. 1169-1176, 2005.

[58] W. Figueiredo, "Men's health care: a challenge for primary care services," Revista Ciência \& Saúde Coletiva, vol. 10, no. 1, pp. 105-109, 2005.

[59] A. J. Tuyns, "Alcohol and cancer. An instructive association," British Journal of Cancer, vol. 64, no. 3, pp. 415-416, 1991.

[60] W. V. Ark, L. J. DiNardo, and D. S. Oliver, "Factors affecting smoking cessation in patients with head and neck cancer," Laryngoscope, vol. 107, no. 7, pp. 888-892, 1997.

[61] World Health Organization, Global Status Report on Noncommunicable Diseases 2010, WHO, Geneva, Switzerland, 2011, http://www.who.int/nmh/publications/ncd_report_full_en.pdf.
[62] F. R. Pinto, L. L. Matos, W. S. Gumz, C. M. R. S. Vanni, D. S. Rosa, and J. L. Kanda, "Tobacco and alcohol use after head and neck cancer treatment: influence of the type of oncological treatment employed," Revista da Associação Médica Brasileira, vol. 57, no. 2, pp. 171-176, 2011.

[63] R. A. Santos, F. B. Portugal, J. D. Felix, P. M. O. Santos, and M. M. Siqueira, "Epidemiological evaluation of patients with cancer in the upper aerodigestive tract: relevance of alcohol and tobacco risk factors," Revista Brasileira de Cancerologia, vol. 58, no. 1, pp. 21-29, 2012. 


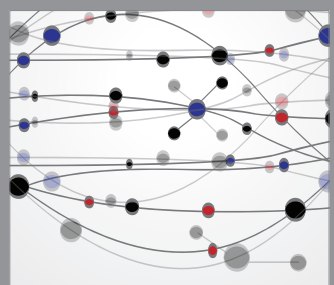

The Scientific World Journal
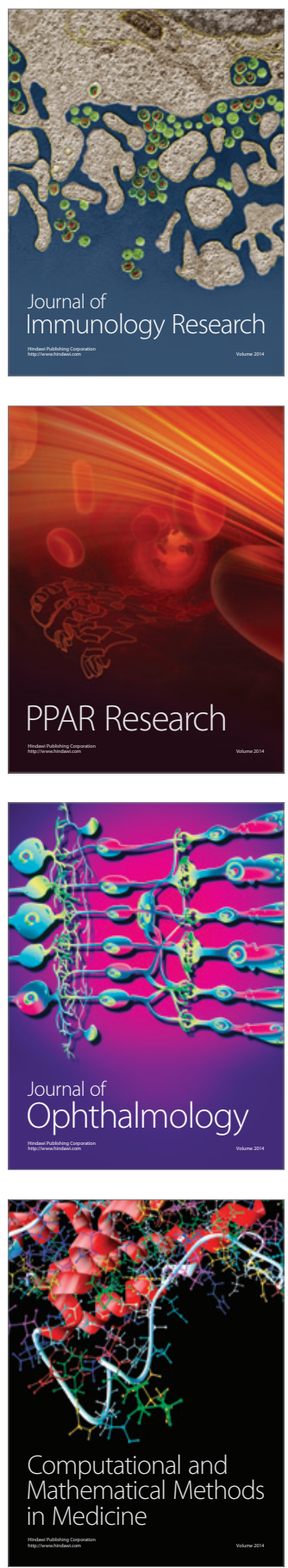

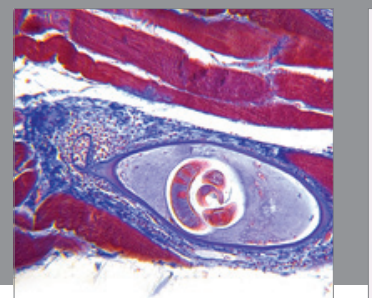

Gastroenterology

Research and Practice
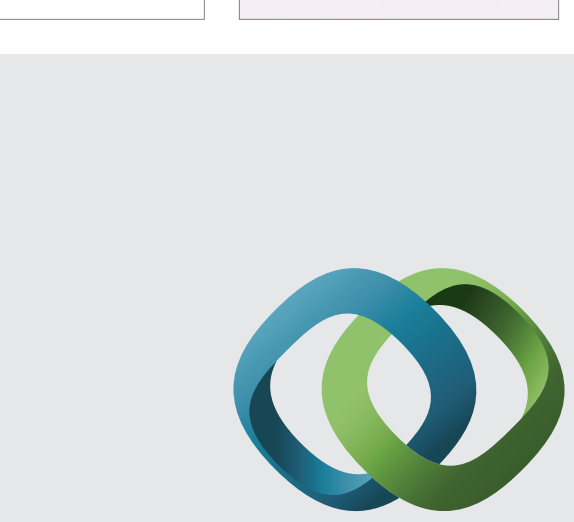

\section{Hindawi}

Submit your manuscripts at

http://www.hindawi.com
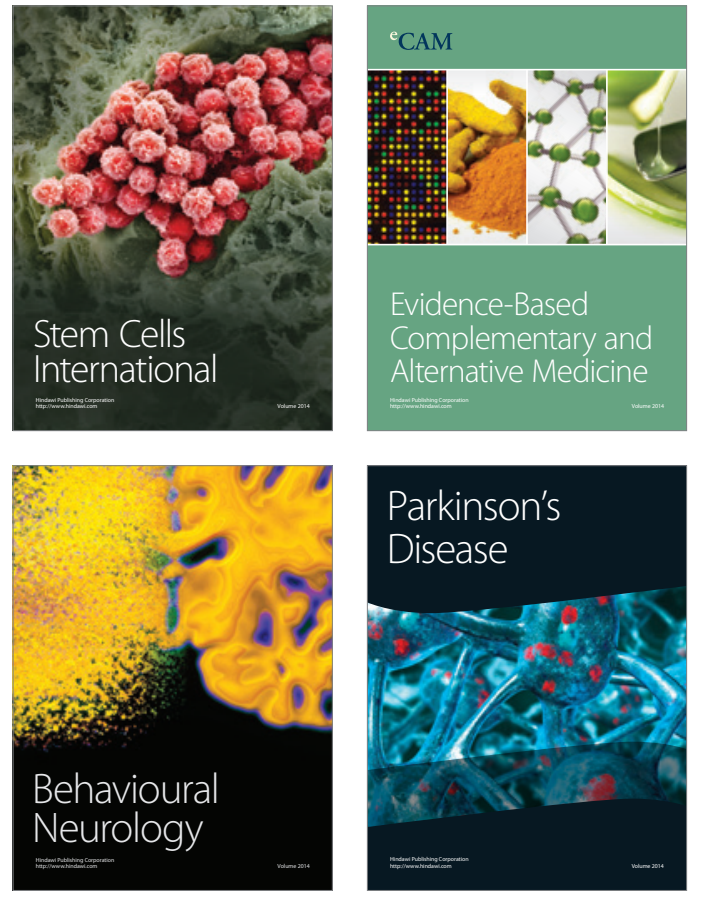
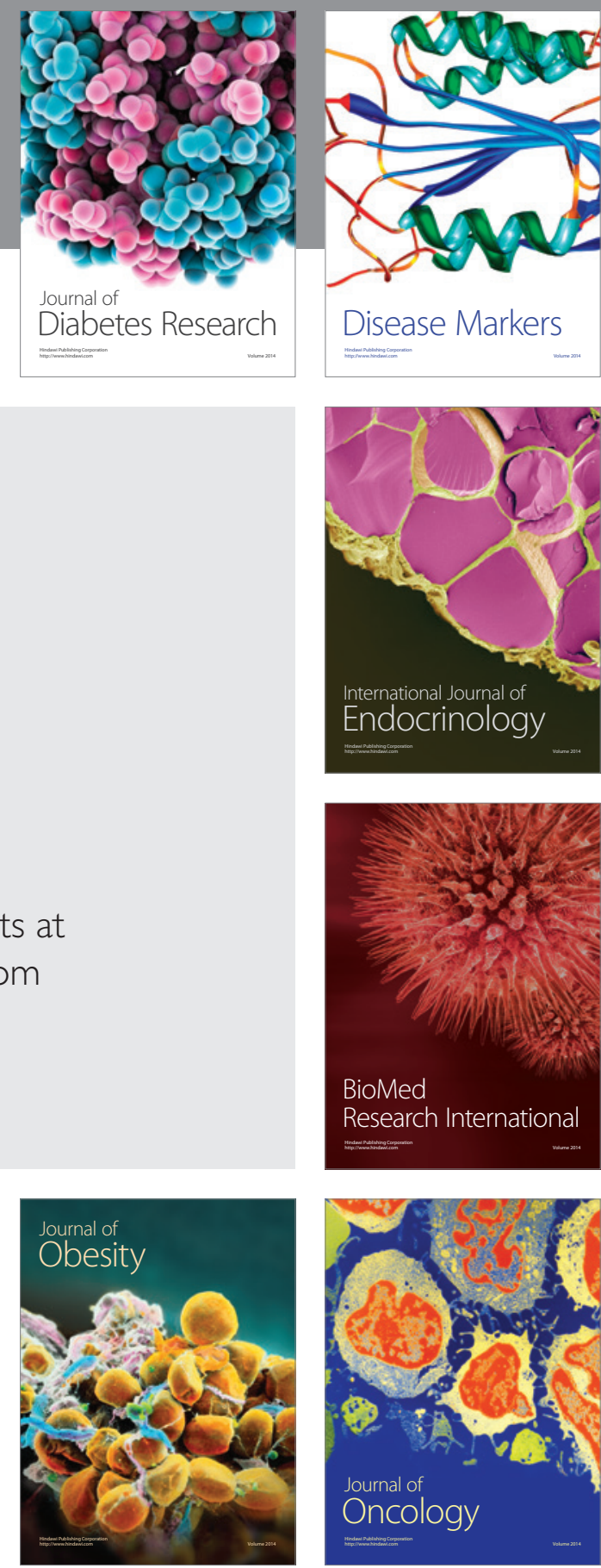

Disease Markers
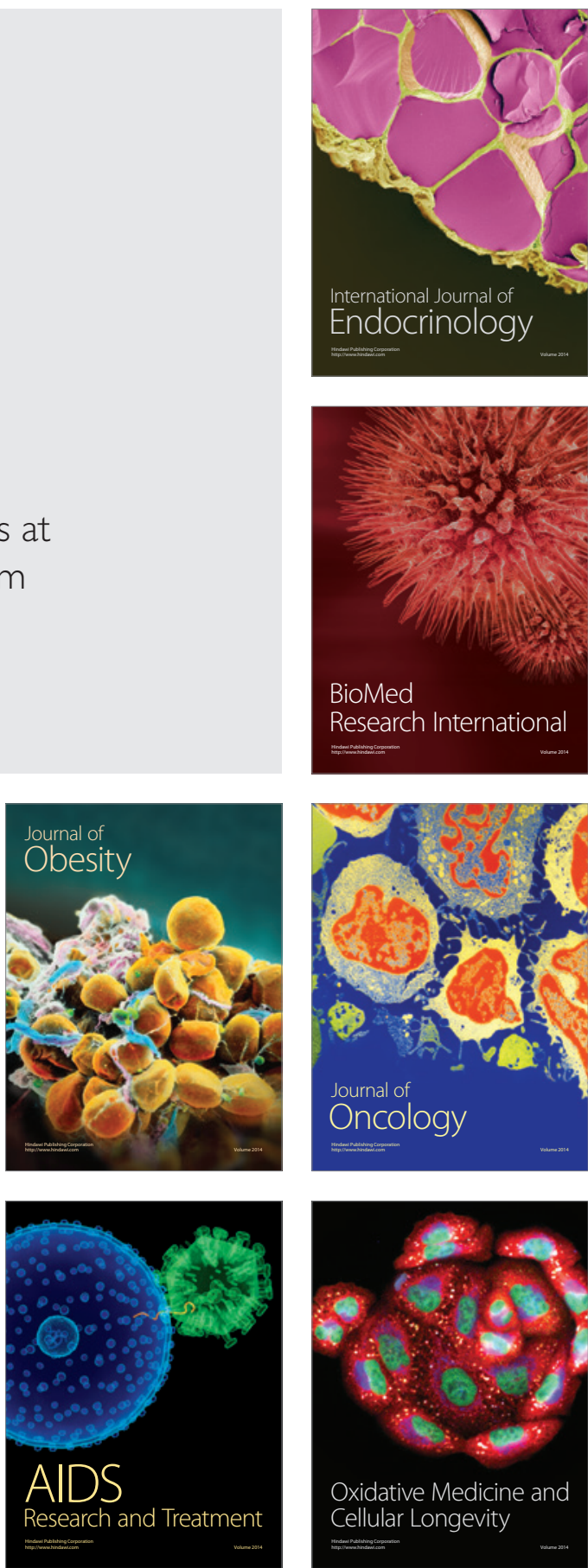